\title{
Acute oxygen therapy: a review of prescribing and delivery practices
}

\author{
This article was published in the following Dove Press journal: \\ International Journal of COPD \\ 24 May 2016 \\ Number of times this article has been viewed
}

\author{
Joyce L Cousins ${ }^{1-3}$ \\ Peter AB Wark ${ }^{3-5}$ \\ Vanessa M McDonald ${ }^{2-5}$ \\ 'Faculty of Arts, Nursing and \\ Theology, Avondale College of Higher \\ Education, Sydney, ${ }^{2}$ School of Nursing \\ and Midwifery, ${ }^{3}$ Priority Research \\ Centre for Healthy Lungs, ${ }^{4} \mathrm{School}$ \\ of Medicine and Public Health, The \\ University of Newcastle, ${ }^{5}$ Department \\ of Respiratory and Sleep Medicine, \\ Hunter Medical Research Institute, \\ John Hunter Hospital, Newcastle, \\ NSW, Australia
}

\begin{abstract}
Oxygen is a commonly used drug in the clinical setting and like other drugs its use must be considered carefully. This is particularly true for those patients who are at risk of type II respiratory failure in whom the risk of hypercapnia is well established. In recent times, several international bodies have advocated for the prescription of oxygen therapy in an attempt to reduce this risk in vulnerable patient groups. Despite this guidance, published data have demonstrated that there has been poor uptake of these recommendations. Multiple interventions have been tested to improve concordance, and while some of these interventions show promise, the sustainability of these interventions are less convincing. In this review, we summarize data that have been published on the prevalence of oxygen prescription and the accurate and appropriate administration of this drug therapy. We also identify strategies that have shown promise in facilitating changes to oxygen prescription and delivery practice. There is a clear need to investigate the barriers, facilitators, and attitudes of clinicians in relation to the prescription of oxygen therapy in acute care. Interventions based on these findings then need to be designed and tested to facilitate the application of evidence-based guidelines to support sustained changes in practice, and ultimately improve patient care.
\end{abstract}

Keywords: chronic obstructive pulmonary disease, COPD, type II respiratory failure, oxygen therapy, prescribing, hypoxia, hypercapnia

\section{Introduction}

Oxygen is a commonly used drug in the clinical setting ${ }^{1-4}$ and unquestionably saves lives. However, its use must be carefully considered. Like any drug, it may cause harm when used inappropriately., ${ }^{4,5}$ In practice, a common misconception that "you can't give too much oxygen" "1,3 or "oxygen won't hurt"4 has emerged. This has led to higher levels of oxygen therapy being delivered to patients who are critically unwell or who complain of dyspnea, ${ }^{3}$ resulting in increased lengths of stay, ${ }^{6}$ higher rates of admission to high dependency units, ${ }^{6}$ and an increased risk of death. ${ }^{7,8}$ Indeed, New ${ }^{9}$ states that in the past ambulance crews regarded oxygen as a sort of "medical wet wipe [...] not always therapeutic, but never harmful."

The clinical effect supplemental oxygen can have on patients experiencing acute exacerbations of chronic obstructive pulmonary disease (COPD) is now widely known, ${ }^{10}$ yet not completely understood. ${ }^{11}$ Uncontrolled oxygen administration, particularly when delivered at high concentrations, can result in a worsening of hypercapnia. ${ }^{12,13}$ Multiple pathological mechanisms are believed to underlie this phenomenon, ${ }^{11,12,14,15}$ with the primary causes being the inhibition of pulmonary vasoconstriction. Resulting in a worse ventilation/perfusion mismatch, and a right-hand shift of the $\mathrm{CO}_{2}$ dissociation curve (Haldane effect), further increasing
Correspondence: Vanessa M McDonald Priority Research Centre for Healthy Lungs, The University of Newcastle, I Kookaburra Circuit, New Lambton Heights, Newcastle, NSW 2305, Australia Tel +6I 240420146 Fax +6I 240420046 Email vanessa.mcdonald@newcastle. edu.au (c) (1) (5) 2016 Cousins et al. This work is published and licensed by Dove Medical Press Limited. The full terms of this license are available at https://www.dovepress.com/terms.php (c) hereby accept the Terms. Non-commercial uses of the work are permitted without any further permission from Dove Medical Press Limited, provided the work is properly attributed. For permission for commercial use of this work, please see paragraphs 4.2 and 5 of our Terms (https://www.dovepress.com/terms.php). 
$\mathrm{P}_{\mathrm{a}} \mathrm{CO}_{2} \cdot{ }^{13,16}$ Other mechanisms for this phenomenon include further increases in ventilation/perfusion mismatching due to absorption atelectasis and an increased work of breathing due to the higher density of oxygen over air. ${ }^{17}$ Initial beliefs that hypercapnia was primarily caused as a result of a "reduced hypoxic drive" have been largely disproved, ${ }^{18}$ following the publication of results challenging these earlier hypothesis. In 1980, Aubier et al ${ }^{18}$ demonstrated that while minute ventilation initially fell with the administration of high concentrations of oxygen therapy in the COPD patient cohort, this decrease was transient, with minute ventilation returning to levels only marginally lower than when breathing room air initially.

For these reasons, the use of titrated oxygen therapy in this patient group has been advocated for many years. Guidance from the British Thoracic Society (BTS), ${ }^{17}$ the Global Initiative for Obstructive Lung Disease ${ }^{19}$ and, more recently, the Thoracic Society of Australia and New Zealand ${ }^{20}$ advise clinicians to administer oxygen to maintain an $\mathrm{SpO}_{2}$ between $88 \%$ and $92 \%$ in an acute hospital setting for patients with COPD and others who are vulnerable. While COPD is the most common chronic disease in clinical practice to cause hypercapnia, ${ }^{17}$ other vulnerable patient groups are also at risk. These include those patients with morbid obesity, obstructive sleep apnea, cystic fibrosis, neuromuscular disorders, those with restrictive chest wall deformities, and those using respiratory depressant drugs, such as opioids and benzodiazepines. ${ }^{17,21}$ In patients who are not at risk of hypercapnic respiratory failure, recommendations vary between professional bodies, with the BTS $\mathrm{S}^{17,21}$ advocating for maintenance of an $\mathrm{SpO}_{2}$ between $94 \%$ and $98 \%$ and the Thoracic Society of Australia and New Zealand ${ }^{20}$ recommending maintenance of an $\mathrm{SpO}_{2}$ between $92 \%$ and $96 \%$. Undoubtedly, the accurate delivery of oxygen therapy is important for all patients; however, the deleterious effects of poor clinical practice in this area are most significant and now well documented in those patients who are vulnerable, particularly those with COPD. ${ }^{7,22-27}$ Austin et $\mathrm{al}^{7}$ were the first to show clear evidence of the benefits of administering titrated oxygen (delivered via nasal prongs to achieve an $\mathrm{SpO}_{2}$ between $88 \%$ and $92 \%$ ) to patients with acute exacerbations of COPD. Their results demonstrated that the delivery of titrated oxygen therapy reduced mortality by $58 \%$ when compared with those who received high flow oxygen therapy (delivered via a nonrebreather mask at $8-10 \mathrm{~L} / \mathrm{min}) .^{7}$ A retrospective review of ambulance practice, conducted by Cameron et al, ${ }^{28}$ illustrates this point. This study demonstrated that $80 \%$ of the patients with COPD brought in to the emergency department by ambulance had received high concentrations of oxygen during initial response and transfer. They reported an increased risk of serious adverse outcomes in patients who were both hypoxemic and hyperoxemic when compared to those who were normoxemic. However, hypercapnia and acidosis were more pronounced in the hyperoxemic group.

Many authors ${ }^{3,11,29-33}$ and professional bodies ${ }^{17,20}$ argue that oxygen should be treated like other drugs with orders for therapy included on a treatment (drug) chart to improve accurate administration. However, prescription of oxygen therapy has been historically poor, and compliance with or adherence to the written prescription has not been consistently demonstrated. This review examines the literature that has explored prescribing practices internationally with a variety of interventions employed in attempts to improve prescription, administration, and consequently patient outcomes.

\section{Oxygen prescription}

The adequacy of oxygen prescription within the acute hospital setting has been studied over many years. ${ }^{34-54}$ These studies have explored both the presence of a prescription and the adequacy and appropriateness of oxygen prescription in a broad range of patient groups. The literature includes studies specific to vulnerable groups, including those with chronic ventilatory failure, but is not limited to this population with evaluation being undertaken in the general clinical setting. However, since the publication of the BTS Guidelines on acute oxygen administration in 2008, there has been an increasing interest in this topic. Figure 1 depicts a timeline of papers (according to the geographical area that the studies were conducted) that have been published on oxygen therapy prescription and administration practices since 1980. Interestingly, over 27 years, between 1980 and 2007,17 papers $^{33,35,41-44,46,47,49-51,53-58}$ were found that discussed oxygen prescription rates and/ or the appropriateness and accuracy of oxygen administration and subsequent monitoring of oxygen therapy. In the 6 years between 2009 and 2015, 12 papers which measured the accurate or appropriate prescription of oxygen therapy have been reported..$^{34,36-40,45,48,52,59-61}$ Some of these papers also discussed various interventions that have been tested to improve prescription practices.

Overall, the literature suggests that the practice of prescribing oxygen therapy is poor. ${ }^{34-39,41-44,46,47,49,51,52}$ 


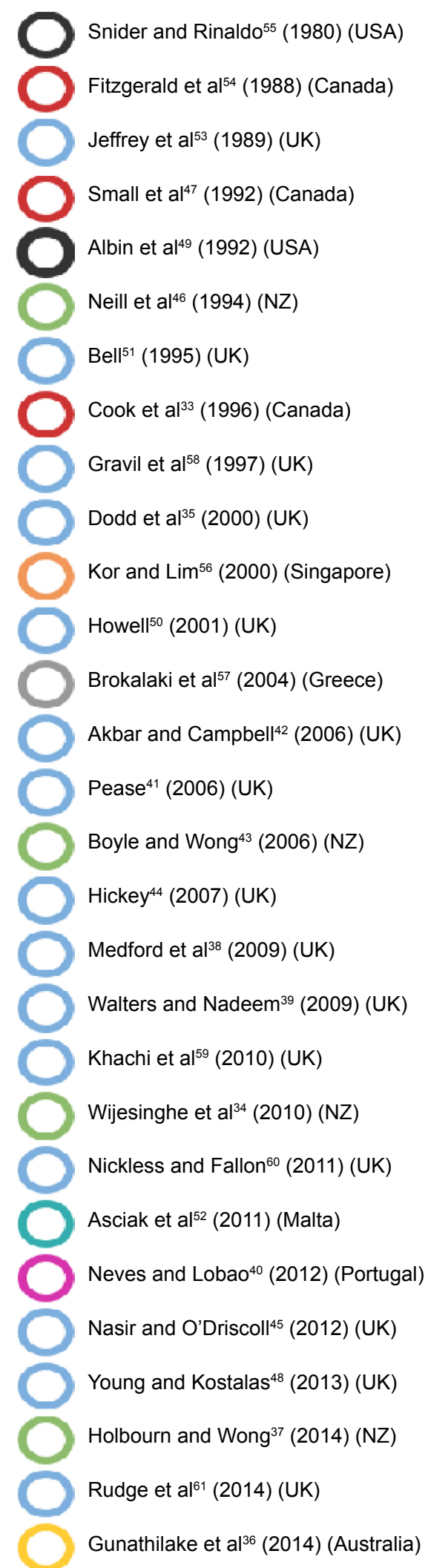

Figure I Timeline of papers published on oxygen therapy prescription and administration practices.

Notes: Between 1980 and 2007 (27 years), 17 papers were found. Between 2009 and 2015 (6 years), 12 papers were found. All papers published between 2009 and 2015 measured the accurate or appropriate prescription of oxygen therapy \pm various interventions to improve prescription rates. 
Various reasons have been proposed for this, including:

- insufficient training and education for medical and nursing staff; $33,39,41,42,47,51,54,62$

- a lack of familiarity with oxygen delivery devices, ${ }^{51}$

- a lack of understanding of the effects, role and dangers of oxygen therapy; $;^{35-37,46,61}$

- staff time constraints; ${ }^{48}$

- necessity to maintain $\mathrm{SpO}_{2}>94 \%$ due to the "between the flags" track and trigger observations charts; ${ }^{36}$

- practical issues related to space and place for prescribing oxygen; ${ }^{35,39,61}$

- difficulties with changing long established behavior; ${ }^{36,60}$

- patients transferred from other wards/departments with oxygen therapy already in situ; ${ }^{44}$

- lack of enthusiasm by senior clinical staff; ${ }^{44}$

- communication difficulties between doctors and nurses, ${ }^{36}$

- lack of full time staff or staff turnover. ${ }^{36,38,48,60}$

In attempts to improve overall prescription rates, different interventions have been tested in various combinations over different periods of time, with varying degrees of success. Interventions that have been employed are presented in Table 1 and the degree of change achieved pre- and postintervention is presented graphically in Figure 2. These interventions include:

- introduction of oxygen alert stickers; $;^{39,59-61}$

- dedicated oxygen order chart; ${ }^{35}$

- clearly delineated section on the drug chart or changes to the drug chart to include space for the transcription of oxygen orders; ${ }^{34-36,48,60}$

- informational posters, ${ }^{59-61}$

- email notification/dissemination of information; ${ }^{60,61}$

- educational session across various clinical specialties and at various key times; ${ }^{34,36,39,44,48,56,59-61}$

- nurse facilitated reminder system; ${ }^{38}$

- development of hospital guidelines/policy to guide practice; $36,42,59,60$

- admission bundle with electronic prescribing system; 45

- message alerts on computer login screens. ${ }^{60}$

One study ${ }^{42}$ demonstrated no or minimal improvement in prescribing practices after implementing an oxygen

Table I Interventions that have been tested in attempts to improve oxygen prescription rates

\begin{tabular}{|c|c|}
\hline Study (year) & Intervention \\
\hline Dodd et $\mathrm{al}^{35}(2000)$ & $\begin{array}{l}\text { - Dedicated oxygen order chart } \\
\text { - Clearly delineated section on the drug chart or changes to the drug chart to include space for the transcription } \\
\text { of oxygen orders }\end{array}$ \\
\hline Akbar and Campbell ${ }^{42}(2006)$ & - Introduction of hospital guidelines \\
\hline Hickey $^{44}$ (2007) & - Educational sessions \\
\hline Medford et al ${ }^{38}$ (2009) & - Nurse facilitated reminder system \\
\hline Walters and Nadeem ${ }^{39}$ (2009) & $\begin{array}{l}\text { - Oxygen alert sticker } \\
\text { - Educational sessions }\end{array}$ \\
\hline Wijesinghe et $\mathrm{al}^{34}(2010)$ & $\begin{array}{l}\text { - Clearly delineated section on the drug chart or changes to the drug chart to include space for the transcription } \\
\text { of oxygen orders } \\
\text { - Educational sessions }\end{array}$ \\
\hline Khachi et $\mathrm{al}^{59}(2010)$ & $\begin{array}{l}\text { - Oxygen alert sticker } \\
\text { - Educational sessions } \\
\text { - Informational posters }\end{array}$ \\
\hline Nickless and Fallon ${ }^{60}(20 \mathrm{II})$ & $\begin{array}{l}\text { - Development of hospital guidelines/policy to guide practice } \\
\text { - Educational sessions } \\
\text { - Informational posters } \\
\text { - Email notification/dissemination } \\
\text { - Message alerts on computer login screen } \\
\text { - Oxygen alert sticker }\end{array}$ \\
\hline Young and Kostalas ${ }^{48}(2013)$ & $\begin{array}{l}\text { - Clearly delineated section on the drug chart or changes to the drug chart to include space for the transcription } \\
\text { of oxygen orders } \\
\text { - Educational sessions }\end{array}$ \\
\hline Gunathilake et $\mathrm{al}^{36}(2014)$ & $\begin{array}{l}\text { - Clearly delineated section on the drug chart or changes to the drug chart to include space for the transcription } \\
\text { of oxygen orders } \\
\text { - Educational sessions } \\
\text { - Development of hospital guidelines/policy to guide practice }\end{array}$ \\
\hline Rudge et al ${ }^{61}(2014)$ & $\begin{array}{l}\text { - Oxygen alert sticker } \\
\text { - Informational posters } \\
\text { - Email notification/dissemination } \\
\text { - Educational sessions }\end{array}$ \\
\hline
\end{tabular}




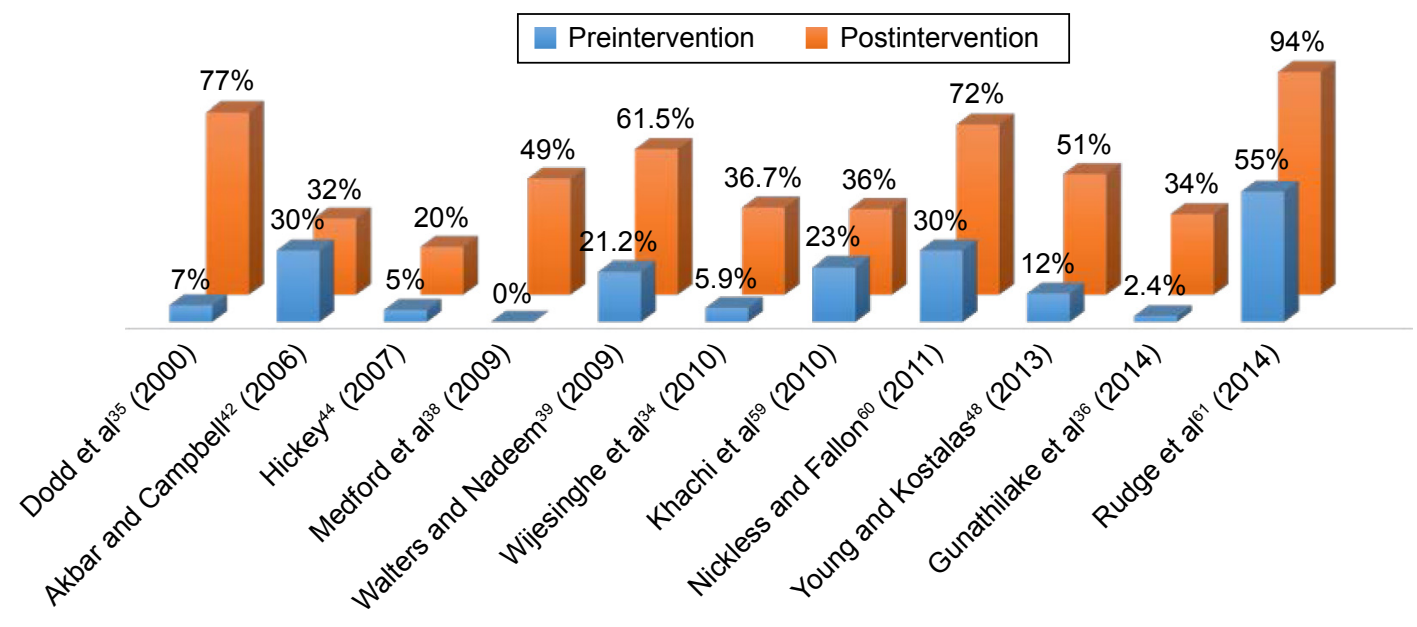

Figure 2 Accurate prescription of oxygen therapy: preintervention-postintervention study results.

Notes: Rates of improvement in prescribing for various interventions.

guideline to inform clinician practice. Despite no change in prescriber behavior, a large improvement was seen in the administration of oxygen according to the prescribed dose ( $70 \%$ vs $95 \% ; P=0.043)$ and in the clinical assessment of all patients commenced on oxygen therapy, that is, increased measurement of pulse oximetry $(69 \%$ vs $91 \% ; P=0.001)$. The assessment of arterial blood gases for those with respiratory disease improved following the introduction of the guideline (from $65 \%$ to $87 \%$; statistical significance was not reported) with even greater improvements seen in the reevaluation of arterial blood gases following initiation of oxygen therapy for the cohort with airways disease, increasing to $68 \%$ from $34 \%(P=0.037)$. The authors ${ }^{42}$ concluded that although little change was seen in the prescribing practices of the doctors, practice improvements were seen. Junior doctors reassessed arterial blood gases more frequently and nurses administered the prescribed dose more frequently and used pulse oximetry more often to assess patients after the introduction of the guidelines. ${ }^{42}$ Similar improvements in administration and assessment have been seen in some practice areas in other studies ${ }^{34,38}$ but not in others ${ }^{47}$ in which the presence of an accurate prescription did not improve oxygen administration and assessment practices in these patients.

Rudge et al ${ }^{61}$ described a promising quality improvement project that occurred over three cycles which demonstrated dramatic improvements to the accurate prescription of oxygen therapy. Baseline data showed that $55 \%$ of patients using oxygen had a valid prescription; this then decreased to $54 \%$ following cycle one, but improved to $94 \%$ at the end of cycle three. They used four interventions (oxygen prescription chart, oxygen alert stickers, point of care resources, and senior led educational sessions) over a 2-year period on an
Acute Medical Unit. ${ }^{61}$ While these data are encouraging, there are limitations with the study design; it was a quality improvement audit conducted in one unit of a single hospital and interventions were ongoing both prior to and during the data collection phase.

Similarly, in an earlier audit undertaken by Dodd et al, ${ }^{35}$ a large improvement was seen in written prescription practice (before and after implementation of a specific oxygen prescription chart, from $55 \%$ to $91 \% ; P=<0.001$ ) with the accuracy of these written prescriptions improving significantly ( $7 \%$ vs $77 \%$; statistical significance was not reported) following the implementation of a dedicated chart on which oxygen therapy could be prescribed. The authors argued that junior doctors have inadequate levels of understanding about the effects and potential dangers of oxygen therapy; however, the improvements seen following the implementation of a dedicated oxygen prescription chart appear to indicate that junior doctors complete required documentation appropriately when it is available and the presence of a chart merely prompted this action. Importantly, this was a single-center study and no data in this study examined the adherence of other clinicians (nurses and other medical staff) to accurately deliver the actual prescription. However, the results from the study by Gunathilake et al ${ }^{36}$ suggest that appropriate oxygen delivery improved as prescription rates improved. They demonstrated that the number of patients at risk of type II respiratory failure with saturation levels above $92 \%$ decreased from $47 \%$ at initial audit to $18 \%(P=0.04)$ following a multicomponent intervention and as prescribing rates increased $(2.4 \%$ to $34 \% ; P=<0.0001) .{ }^{36}$ Despite these encouraging results that demonstrate improvements in practice are possible, the sustainability of this behavior has been questioned by Young and Kostalas. ${ }^{48}$ They saw a 
significant improvement in prescription rates (from $12 \%$ to $74 \%$; $P=<0.001) 3$ months following the introduction of an oxygen prescription section on the drug chart and the delivery of an educational session, but at 12 months this had decreased to $51 \%$.

Also of interest is a study by Medford et $\mathrm{al}^{38}$ who implemented a nurse facilitated reminder system and found that there were relatively high rates of appropriate oxygen administration prior to the implementation of the reminder system, and that these did not change significantly on reaudit 4 months after implementation $(70.6 \%$ and $76.5 \%$, respectively; $P=0.65)$. Here, nurses were empowered to remind doctors to prescribe oxygen therapy. This may indicate that in general, nurses are skilled at delivering the appropriate dose of oxygen despite the absence of a prescription as is indicated by the lack of practice change by the nurses and maintenance of a relatively high rate of appropriate administration of oxygen therapy both before and after the intervention.

\section{Knowledge of oxygen therapy and delivery equipment}

Knowledge of oxygen therapy and the equipment used to deliver oxygen may also be barriers to optimal oxygen administration. This has been highlighted in a study conducted by Ganeshan et $\mathrm{al}^{62}$ who reported that commonly used oxygen delivery devices, for example, nasal cannulae, are easily recognized by doctors and nurses with less frequently used devices, such as nonrebreathing masks, being poorly recognized. In addition, when both medical and nursing clinicians were presented with sample case scenarios, a larger proportion (up $97 \%$ and $73 \%$ of doctors and nurses, respectively) were not able to accurately prescribe the correct dose of oxygen or the appropriate method for administration of oxygen for some of the scenarios described. Interestingly, this study ${ }^{62}$ demonstrated that in four out of the seven case scenarios, nurses' knowledge of the correct delivery devices and oxygen prescription was higher than that of the doctors. Overall, however, knowledge of correct prescriptions was suboptimal.

The authors argue that even if it were compulsory for medical staff to complete written prescriptions of oxygen therapy in wards settings, it is unlikely that staff would be able to prescribe it correctly. These findings are of particular concern in light of the current guideline recommendations. ${ }^{17,20}$ Disturbingly, these are not stand alone results and are supported by findings from other studies ${ }^{63-65}$ that show there are large gaps in the knowledge of health care staff on various aspects of respiratory therapy. Considering the frequency with which oxygen is administered in an acute hospital setting and the harm that may be caused, interventions to improve the overall knowledge and practice around oxygen therapy and therefore concordance to evidence-based guidelines are urgently required.

\section{Auditing practice}

The BTS has conducted audits of prescribing practices within the National Health Service (NHS) since the implementation of the 2008 guidelines. These audits have demonstrated slow but steady improvements in the rates of oxygen prescription. The most recently available data from the 2013 audit $^{66}$ demonstrated that $55 \%$ of patients who were using oxygen had some form of written order. This is an improvement from the 2008 audit which showed that only $32 \%$ of patients had a written order. ${ }^{66}$ These data also demonstrate a steady decline $(17.5 \%$ down to $13.8 \%)$ in the number of patients within the NHS who are using oxygen therapy, ${ }^{66}$ which could result in improved patient outcomes and substantial savings for the health service. In contrast, an Australian audit demonstrated that as few as 3\% of patients with COPD had an existing oxygen prescription despite $79 \%$ of patients with COPD receiving oxygen therapy at the time of audit. ${ }^{27}$ This improved level of practice in the UK, where regular audits are performed, may indicate that regular auditing and review of clinical practice and practice gaps can lead to improved clinician behavior.

\section{Current recommendations and future directions}

The NHS in their latest oxygen safety report ${ }^{67}$ suggests that the main safety concerns for oxygen administration relate to the under- and overuse of oxygen, and that these are caused by the inappropriate prescription, monitoring, and administration of oxygen. Like the BTS, the NHS emphasizes the need for the accurate prescription and monitoring of patients with pulse oximetry. Similarly, the 2015 Thoracic Society of Australia and New Zealand guidelines for acute oxygen use in adults also recommend that oxygen therapy is prescribed with a specific record documented in the patient notes and drug chart, the main requirements being the documentation of a target $\mathrm{SpO}_{2}$ range.

It is clear that there is a need to improve the prescribing practices for all patients across hospital settings. Although the authors have postulated on the reasons behind why evidence-based guidelines are not adhered to, very little data exist examining why high flow oxygen continues to be given in practice (particularly in the prehospital and emergency department setting) or why the written prescription of 
oxygen therapy remains low. Medford et $\mathrm{al}^{38}$ and Hickey ${ }^{44}$ suggest that analysis of doctors' views on the prescription of oxygen therapy is needed and that strategies for optimizing the behavior of permanent nursing staff are necessary; ${ }^{38}$ however, to date, few data have been published relating to these points. As such, little is known about the barriers or facilitators that exist to improve the implementation of these strategies in practice, yet, published literature from the past 30 years demonstrates that despite a number of interventional strategies aimed at improving practice, it continues to be a challenging practice to change.

The knowledge practice gap is a common phenomenon in health care ${ }^{68}$ with some authors ${ }^{69}$ suggesting that the provision of guidelines and evidence from research, while necessary, are not sufficient in bridging the knowledge practice gap. Specifically, this has been demonstrated with the oxygen prescription data. A convincing evidence base now exists, yet the consistent application of the evidence (prescription and delivery of low flow oxygen to maintain $\mathrm{SpO}_{2} 88 \%-92 \%$ in vulnerable patient groups) is not applied in daily practice. Funk et $\mathrm{al}^{70}$ argue that determining the perceptions of clinicians is vital in addressing this knowledge-practice gap. Ultimately, clinicians are responsible for the delivery of care. If we are to reduce or eliminate barriers to implementing research knowledge into practice, clinicians' opinions are vital. Tailored interventions while effective can be variable; however, a 2015 Cochrane Review concluded that "interventions tailored to address identified barriers are probably more likely to improve professional practice than no intervention or the dissemination of guidelines alone." ${ }^{.71}$

\section{Conclusion}

Throughout this review, we have presented international data surrounding current practice for the prescription of oxygen therapy. These data demonstrate that the rates of concordance to recommended practice have seen a necessary change in oxygen prescription; however, there remains substantial room for improvement. This is evidenced in the large audit conducted by Roberts et $\mathrm{al}^{26}$ in 2010-2011 in which 16,018 patients admitted with acute exacerbations of COPD to hospitals in 13 European countries demonstrated a high level of adherence (85\%) to the Global Initiative for Obstructive Lung Disease ${ }^{72}$ standards for the management of acute exacerbations of COPD, administering titrated oxygen therapy, to achieve $\mathrm{PaO}_{2}>60 \mathrm{mmHg}$ or $\mathrm{SpO}_{2}>90 \%{ }^{72}$ Despite this high level of adherence, $>1,623(10.1 \%)$ of the patients across the hospitals received either high flow oxygen or no supplemental oxygen (despite being hypoxic).
Many practice gaps exist, which lead to poor patient outcomes. Pilcher and Beasley ${ }^{32}$ suggest that there is an entrenched culture of routine and indiscriminate administration of high-concentration oxygen to acutely ill patients. This culture must change and there is a clear need to examine the barriers, facilitators, and attitudes toward oxygen and its prescription in acute care if we are to improve practice and minimize harm in vulnerable patient groups. Effective interventions may assist in translating expert guidelines into clinical practice. These may facilitate the adoption of best practice guidelines and ultimately improve clinical outcomes for COPD and other vulnerable patient groups who are most impacted by poor oxygen administration practices.

\section{Acknowledgment}

VM McDonald is supported by a National Health and Medical Research Council Translating Research into Practice Fellowship.

\section{Disclosure}

The authors report no conflicts of interest in this work.

\section{References}

1. Martin DS, Grocott MP III. Oxygen therapy in anaesthesia: the yin and yang of $\mathrm{O}_{2}$. Br J Anaesth. 2013;111(6):867-871.

2. Steinman Kaufman J, Kent B. Nursing management: obstructive pulmonary diseases. In: Brown P, Edwards H, Seaton L, et al, editors. Lewis's Medical-Surgical Nursing. Assessment and Management of Clinical Problems. Australia and New Zealand Edition. 4th ed. Sydney: Mosby Elsevier; 2015:564-614.

3. Kane B, Decalmer S, O'Driscoll BR. Emergency oxygen therapy: from guideline to implementation. Breathe. 2013;9(4):246-253.

4. Blakeman TC. Evidence for oxygen use in the hospitalized patient: is more really the enemy of good? Respir Care. 2013;58(10):1679-1693.

5. Martin DS, Grocott MPW. Oxygen therapy and anaesthesia: too much of a good thing? Anaesthesia. 2015;70(5):518-522.

6. Joosten SA, Koh MS, Bu X, Smallwood D, Irving LB. The effects of oxygen therapy in patients presenting to an emergency department with exacerbation of chronic obstructive pulmonary disease. Med J Aust. 2007; 186(5):235-238.

7. Austin MA, Willis KE, Blizzard L, Walters EH, Wood-Baker R. Effect of high flow oxygen on mortality in chronic obstructive pulmonary disease patients in prehospital setting: randomised controlled trial. BMJ. 2010; 341(c5462).

8. Wijesinghe M, Perrin K, Healy B, et al. Pre-hospital oxygen therapy in acute exacerbations of chronic obstructive pulmonary disease. Intern Med J. 2011;41(8):618-622.

9. New A. Oxygen: kill or cure? Prehospital hyperoxia in the COPD patient. Emerg Med J. 2006;23(2):144-146.

10. McDonald CF. Oxygen therapy for COPD. J Thorac Dis. 2014;6(11): 1632-1639.

11. Brill SE, Wedzicha JA. Oxygen therapy in acute exacerbations of chronic obstructive pulmonary disease. Int J Chron Obstruct Pulmon Dis. 2014;9:1241-1252.

12. Bosson N, Gausche-Hill M, Koenig W. Implementation of a titrated oxygen protocol in the out-of-hospital setting. Prehosp Disaster Med. 2014;29(4):403-408. 
13. Abdo WF, Heunks LMA. Oxygen-induced hypercapnia in COPD: myths and facts. Critical Care. 2012;16(323):4.

14. Roca M, Verduri A, Corbetta L, Clini E, Fabbri LM, Beghé B. Mechanisms of acute exacerbation of respiratory symptoms in chronic obstructive pulmonary disease. Eur J Clin Invest. 2013;43(5):510-521.

15. Abramson MJ, Crockett AJ, Dabscheck E, et al. The COPDX Plan: Australian and New Zealand Guidelines for the management of Chronic Obstructive Pulmonary Disease. 2014:1-111.

16. Littleton SW. Hypercapnia from hyperoxia in COPD: Another piece of the puzzle or another puzzle entirely? Respir Care. 2015;60(3):473-475.

17. O'Driscoll BR, Howard LS, Davison AG; British Thoracic Society. BTS guideline for emergency oxygen use in adult patients. Thorax. 2008; 63 Suppl 6:vi1-vi68.

18. Aubier M, Murciano D, Milic-Emili J, et al. Effects of the administration of $\mathrm{O}_{2}$ on ventilation and blood gases in patients with chronic obstructive pulmonary disease during acute respiratory failure. Am Rev Respir Dis. 1980;122(5):747-754.

19. Global Initiative for Chronic Obstructive Lung Disease (GOLD). Global Strategy for the Diagnosis, management, and Prevention of Chronic Obstructive Pulmonary Disease [updated 2016]; 2016:i-111. Available from: http://www.goldcopd.org/uploads/users/files/WatermarkedGobal\%20 Strategy\%202016\%281\%29.pdf. Accessed February 19, 2016.

20. Beasley R, Chien J, Douglas J, et al. Thoracic Society of Australia and New Zealand oxygen guidelines for acute oxygen use in adults: 'Swimming between the flags'. Respirology. 2015;20(8):1182-1191.

21. O'Driscoll BR, Howard L, Earis J, Mak V; BTS Emergency Oxygen Guideline Group. BTS Guidelines for oxygen use in adults in healthcare and emergency settings [Public consultation draft]. 2015. Available from: https://www.brit-thoracic.org.uk/document-library/ clinical-information/oxygen/emergency-oxygen-guideline-2015/btsfull-guideline-for-oxygen-use-in-adults-in-healthcare-and-emergencysettings-2015/

22. Chow JW, Khullar K, Katechia K, Klim S, Kelly AM. Do ambulance paramedics administer too much oxygen to patients with acute exacerbations of chronic obstructive airways disease? [Letter to the editor]. Emerg Med Australas. 2015;27(3):275-276.

23. Susanto C, Thomas PS. Assessing the use of initial oxygen therapy in chronic obstructive pulmonary disease patients: a retrospective audit of pre-hospital and hospital emergency management. Intern Med J. 2015; 45(5):510-516.

24. Gooptu B, Ward L, Ansari SO, Eraut CD, Law D, Davison AG. Oxygen alert cards and controlled oxygen: preventing emergency admissions at risk of hypercapnic acidosis receiving high inspired oxygen concentrations in ambulances and A\&E departments. Emerg Med J. 2006;23(8):636-638.

25. Pilcher J, Cameron L, Braithwaite I, et al. Comparative audit of oxygen use in the prehospital setting in acute COPD exacerbation over 5 years. Emerg Med J. 2015;32(3):234-238.

26. Roberts CM, Lopez-Campos JL, Pozo-Rodriguez F, Hartl S; European COPD Audit team. European hospital adherence to GOLD recommendations for chronic obstructive pulmonary disease (COPD) exacerbation admissions. Thorax. 2013;68(12):1169-1171.

27. Pretto JJ, McDonald VM, Wark PA, Hensley MJ. Multicentre audit of inpatient management of acute exacerbations of chronic obstructive pulmonary disease: comparison with clinical guidelines. Intern Med J. 2012;42(4):380-387.

28. Cameron L, Pilcher J, Weatherall M, Beasley R, Perrin K. The risk of serious adverse outcomes associated with hypoxaemia and hyperoxaemia in acute exacerbations of COPD. Postgrad Med J. 2012; 88(1046):684-689.

29. Al-Shaqsi S, Brockway B. ABC of oxygen therapy in acute care: Why? Who? How? N Z Med Student J. 2013;17:5-8.

30. Slade S. Evidence summary: oxygen therapy: hospital setting. The Joanna Briggs Institute; 2014.

31. Lamont T, Luettel D, Scarpello J, O'Driscoll BR, Connew S. Improving the safety of oxygen therapy in hospitals: summary of a safety report from the National Patient Safety Agency. BMJ. 2010;340:313-314.
32. Pilcher J, Beasley R. Acute use of oxygen therapy. Aust Prescr. 2015; 38(3):98-100.

33. Cook DJ, Reeve BK, Griffith LE, Mookadam F, Gibson JC. Multidisciplinary education for oxygen prescription: A continuous quality improvement study. Arch Intern Med. 1996;156(16):1797-1801.

34. Wijesinghe M, Shirtcliffe P, Perrin K, et al. An audit of the effect of oxygen prescription charts on clinical practice. Postgrad Med J. 2010; 86(1012):89-93.

35. Dodd ME, Kellet F, Davis A, et al. Audit of oxygen prescribing before and after the introduction of a prescription chart. BMJ. 2000; 321:864-865.

36. Gunathilake R, Lowe D, Wills J, Knight A, Braude P. Implementation of a multicomponent intervention to optimise patient safety through improved oxygen prescription in a rural hospital. Aust J Rural Health. 2014;22(6):328-333.

37. Holbourn A, Wong J. Oxygen prescribing practice at Waikato Hospital does not meet guideline recommendations. Intern Med J. 2014; 44(12a):1231-1234

38. Medford A, Bowen J, Harvey J. Improved oxygen prescribing using a nurse-facilitated reminder. Br J Nurs. 2009;18(12):730-734.

39. Walters $G$, Nadeem $S$. Improving acute oxygen prescription in a respiratory care unit. Qual Saf Health Care. 2009;18(6):512.

40. Neves JT, Lobão MJ; Grupo de trabalho EMO. Oxygen therapy multicentric study - a nationwide audit to oxygen therapy procedures in internal medicine wards. Rev Port Pneumol. 2012;18(2): $80-85$.

41. Pease P. Oxygen administration: is practice based on evidence? Paediatr Nurs. 2006;18(8):14-18.

42. Akbar FA, Campbell IA. Oxygen therapy in hospitalized patients: the impact of local guidelines. J Eval Clin Pract. 2006;12(1):31-36.

43. Boyle M, Wong J. Prescribing oxygen therapy. An audit of oxygen prescribing practices on medical wards at North Shore Hospital, Auckland, New Zealand. N Z Med J. 2006;119(1238):U2080.

44. Hickey S. An audit of oxygen therapy on a respiratory ward. Br J Nurs. 2007;16(18):1132-1136.

45. Nasir AA, O'Driscoll BR. P45 Audit of oxygen management on nine medical wards using electronic prescribing systems. Poster presented at: British Thoracic Society Winter Meeting 2012; December 5-7, 2012; Westminster, London, UK

46. Neill AM, Epton MJ, Martin IR, Drennan CJ, Town GI. An audit of the assessment and management of patients admitted to Christchurch Hospital with chronic obstructive pulmonary disease. NZ Med J. 1994; 107(986 Pt 1):365-367.

47. Small D, Duha A, Wieskopf B, et al. Uses and misuses of oxygen in hospitalized patients. Am J Med. 1992;92:591-595.

48. Young AF, Kostalas M. The acute prescription of oxygen in orthopaedic trauma patients. Br J Hosp Med. 2013;74(10):586-589.

49. Albin RJ, Criner GJ, Thomas S, Abou-Jaoude S. Pattern of non-ICU inpatient supplemental oxygen utilization in a University Hospital. Chest. 1992;102(6):1672-1675.

50. Howell M. An audit of oxygen prescribing in acute general medical wards. Prof Nurse. 2001;17(4):221-224.

51. Bell C. Is this what the doctor ordered? Accuracy of oxygen therapy prescribed in hospital. Prof Nurse. 1995;10(5):279-300.

52. Asciak R, Fenech VA, Gatt J, Montefort S. Oxygen prescription and administration at the emergency department and medical wards in Mater Dei Hospital. Malta Med J. 2011;23(2):19-23.

53. Jeffrey AA, Ray S, Douglas NJ. Accuracy of inpatient oxygen administration. Thorax. 1989;44:1036-1037.

54. Fitzgerald JM, Baynham R, Powles AC. Use of oxygen therapy for adult patients outside of the critical care areas of a university hospital. Lancet. 1988;1(8592):981-983.

55. Snider GL, Rinaldo JE. Oxygen therapy in medical patients hospitalized outside of the intensive care unit. Am Rev Respir Dis. 1980;122:29-36.

56. Kor AC, Lim TK. Audit of oxygen therapy in acute general medical wards following an educational programme. Ann Acad Med Singapore. 2000;29:177-181. 
57. Brokalaki H, Matziou V, Zyga S, et al. Omissions and errors during oxygen therapy of hospitalized patients in a large city of Greece. Intensive Crit Care Nurs. 2004;20(6):352-357.

58. Gravil JH, O'Neill VJ, Stevenson RD. Audit of oxygen therapy. Int J Clin Pract. 1997;51(4):217-218.

59. Khachi H, Burman M, Walters L, Sinha-Ray R, Antoniou S, Mandal S. P84 the impact of a multidisciplinary educational programme on the prescribing of oxygen in an acute trust. Thorax. 2010;65(Suppl 4): A112-A113.

60. Nickless G, Fallon R. Improving local compliance with standards for oxygen prescribing. Clin Pharm. 2011;3:299. Available from: http:// www.pharmaceutical-journal.com/news-and-analysis/news/improvinglocal-compliance-with-standards-for-oxygen-prescribing/11085599. article

61. Rudge J, Odedra S, Harrison D. A new oxygen prescription produces real improvements in therapeutic oxygen use. BMJ Qual Improv Reports. 2014;3(1). doi:10.1136/bmjquality.u204031.w1815.

62. Ganeshan A, Hon LQ, Soonawalla ZF. Oxygen: Can we prescribe it correctly? Eur J Intern Med. 2006;17(5):355-359.

63. Smith GB, Poplett N. Knowledge of aspects of acute care in trainee doctors. Postgrad Med J. 2002;78(920):335-338.

64. Esposito S, Brivio A, Tagliabue C, et al. Knowledge of oxygen administration, aerosol medicine, and chest physiotherapy among pediatric healthcare workers in Italy. J Aerosol Med Pulm Drug Deliv. 2011;24(3) $149-156$.

65. Eastwood GM, Reade MC, Peck L, Baldwin I, Considine J, Bellomo R. Critical care nurses' opinion and self-reported practice of oxygen therapy: a survey. Aust Crit Care. 2012;25(1):23-30.
66. O'Driscoll BR. British Thoracic Society Emergency Oxygen Audit 2013 (National Audit Period 15 August-1 November 2013). 2014. Available from: https://www.brit-thoracic.org.uk/document-library/ audit-and-quality-improvement/audit-reports/bts-emergency-oxygenaudit-report-2013/

67. National Health Service. Rapid Response Report NPSA/2009/RRR006: Oxygen safety in hospitals; 2009. Available from: http://www.nrls.npsa. nhs.uk/resources $/$ ?entryid $45=62811$

68. Grol R, Wensing W. What drives change? Barriers to and incentives for achieving evidence-based practice. Med J Aust. 2004;180:S57-S60.

69. Straus SE, Tetroe J, Graham ID. Knowledge translation: what it is and what it isn't. In: Straus SE, Tetroe J, Graham ID, editors. Knowledge Translation in Health Care. Moving from Evidence to Practice. 2nd ed. Chichester: Wiley; 2013:3-13.

70. Funk SG, Champagne MT, Wiese RA, Tornquist EM. BARRIERS The barriers to research utilization scale. Appl Nurs Res. 1991;4(1): 39-45

71. Baker R, Camosso-Stefinovic J, Gillies C, et al. Tailored interventions to address determinants of practice. Cochrane Database of Systematic Reviews Cochrane Database Syst Rev. 2015(4):i-118. Available from: http://onlinelibrary.wiley.com/doi/10.1002/14651858.CD005470. pub3/abstract;jsessionid=1F4B90BD5BCD52658D574021CA65C97 B.f03t03

72. Global Initiative for Chronic Obstructive Lung Disease (GOLD). Global strategy for the diagnosis, management, and prevention of chronic obstructive pulmonary disease [updated 2010]; 2010:i-117. Available from: http://www.goldcopd.org/uploads/users/files/ GOLDReport_April112011.pdf. Accessed 19th February 2016.
International Journal of COPD

\section{Publish your work in this journal}

The International Journal of COPD is an international, peer-reviewed journal of therapeutics and pharmacology focusing on concise rapid reporting of clinical studies and reviews in COPD. Special focus is given to the pathophysiological processes underlying the disease, intervention programs, patient focused education, and self management protocols.

\section{Dovepress}

This journal is indexed on PubMed Central, MedLine and CAS. The manuscript management system is completely online and includes a very quick and fair peer-review system, which is all easy to use. Visit http://www.dovepress.com/testimonials.php to read real quotes from published authors. 